\title{
Fetal-Maternal Surgery for Spina Bifida in a HIV-Infected Mother
}

\author{
Julia Elrod ${ }^{\text {a, b, c }}$ Nicole Ochsenbein-Kölble ${ }^{b, d} \quad$ Luca Mazzone $^{\text {a, b, c }}$ \\ Roland Zimmermann ${ }^{\text {b, d }}$ Christoph Berger ${ }^{c, e}$ Roberto F. Speck ${ }^{f}$ \\ Nele Strübing ${ }^{b, d}$ Christoph Mohr ${ }^{a}$ Ueli Moehrlen ${ }^{a, b, c}$ Martin Meulia,b,c
}

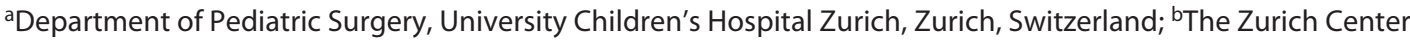
for Fetal Diagnosis and Therapy, University of Zurich, Zurich, Switzerland; ' ${ }^{C}$ Children's Research Center (CRC), University Children's Hospital Zurich, Zurich, Switzerland; 'Department of Obstetrics, University Hospital Zurich, Zurich, Switzerland; 'Division of Infectious Diseases and Hospital Epidemiology, University Children's Hospital Zurich, Zurich, Switzerland; fDivision of Infectious Diseases and Hospital Epidemiology, University Hospital Zurich, Zurich, Switzerland

\section{Established Facts}

- In utero surgery for MMC produces better outcomes than postnatal repair.

- In utero surgery potentially increases the risk of mother-to-child transmission of infectious diseases, such as HIV.

- Highly active antiretroviral therapy is very effective in reducing vertical transmission of HIV from the mother to the child.

\section{Novel Insights}

- It appears possible to devise a monitoring and treatment plan to allow maternal-fetal surgery for MMC in a HIV-positive mother with a risk of vertical HIV transmission not exceeding the one present with postnatal care.

- The regimen includes standard highly active antiretroviral therapy for the mother throughout the entire pregnancy and open maternal-fetal surgery under perioperative intravenous therapy with zidovudine.

- This case is a surrogate for moving toward personalized medicine by postulating that eligibility for maternal-fetal surgery should and can be evaluated on a case to case basis.

\section{Keywords}

Myelomeningocele - Maternal-fetal surgery · HIV

Post-exposure prophylaxis · Zidovudine

Ueli Moehrlen and Martin Meuli share last authorship.

karger@karger.com www.karger.com/fdt

Karger $\stackrel{\text { ' }}{5}$
(C) 2022 The Author(s)

Published by S. Karger AG, Basel

This is an Open Access article licensed under the Creative Common Attribution-NonCommercial-4.0 International License (CC BY-NC) (http://www.karger.com/Services/OpenAccessLicense), applicable to the online version of the article only. Usage and distribution for commercial purposes requires written permission.

\section{Abstract}

Introduction: In select cases, in utero surgery for myelomeningocele (MMC) leads to better outcomes than postnatal repair. However, maternal HIV infection constitutes a formal exclusion criterion due to the potential of vertical HIV transmission. Encouraged by a previous case of a successful fetal 
spina bifida repair in a Hepatitis Bs antigen-positive woman, a plan was devised allowing for fetal surgery. Case Report: In utero MMC repair was performed although the mother was HIV-infected. To minimize the risk of in utero HIV transmission, the mother was treated by highly active antiretroviral therapy throughout gestation as well as intravenous zidovudine administration during maternal-fetal surgery. The mother tolerated all procedures very well without any sequelae. The currently 20 month-old toddler is HIV negative and has significantly benefitted from fetal surgery. Discussion/Conclusion: This case shows that maternal HIV is not a priori a diagnosis that excludes fetal surgery. Rather, it might be a surrogate for moving towards personalized medicine and away from applying too rigorous exclusion criteria in the selection of candidates for maternal-fetal surgery.

(c) 2022 The Author(s).

Published by S. Karger AG, Basel

\section{Introduction}

We recently published the first case report of an active and passive in utero vaccination against Hepatitis $B$ virus infection of a spina bifida fetus carried by a HBs antigenpositive mother, allowing for safe maternal-fetal surgery [1]. The boy benefitted maximally from spina bifida repair with regard to the absence of hydrocephalus-shunting, presentation of normal bladder and anorectal functions, and the ability to ambulate independently [1]. These findings are most likely attributable to fetal surgery [2-5]. The procedure was done after a multidisciplinary expert team had devised a maternal treatment and fetal in utero vaccination plan, allowing surgery to be performed with a risk minimized as much as possible [1].

Shortly afterward, we have been challenged with a case of spina bifida needing fetal surgery, from a HIV-infected mother. Based on the risk of vertical HIV transmission, the kid would have been noneligible for in utero MMC according to the MOMS criteria [2]. Encouraged by the above described case, we have been searching for another strategy to do MMC repair in this HIV-infected mother.

\section{Case Report}

At her first visit, the 31-year-old mother was in the 22nd week of gestation. Ultrasound and fetal MRI had confirmed the diagnosis of MMC (upper level lumbar 3), Chiari II malformation with cerebellar herniation, and no evidence for clubfeet.

The mother suffered from asymptomatic HIV infection with a nondetectable viral load and $714(43 \%) \mathrm{CD} 4-$ cells $/ \mathrm{mm}^{3}$. The Highly active antiretroviral therapy (HAART) consisted of Lamivudine,
Tenofovir, and Lopinavir/Ritonavir. Otherwise mother and fetus qualified for fetal surgery without reservation. Contrary to a previous publication [6] recently linked data from birth defect surveillance- and HIV programs has now revealed the prevalence of neural tube defects among women with HIV (7.0 per 10,000 live births) not to differ significantly from the general incidence of (neural tube defect) [7].

Thorough considerations involving obstetricians, specialists in pediatric and adult infectious disease with special expertise in maternal-fetal transmission, and fetal surgeons resulted in a treatment proposal allowing for in utero defect closure with a minimized risk of mother-to-child transmission (MTCT) of HIV. Prior to surgery, a full disclosure, nondirective standard patient counseling was carried out and informed consent was obtained.

The HAART was continued throughout the entire pregnancy. Viral load in the blood was monitored throughout gestation and was always below detection limit as was the viral load in the amniotic fluid determined at $24+4$ weeks of gestation.

At $25+4$ weeks of gestation, open maternal-fetal surgery was performed under perioperative i.v. therapy of the mother with zidovudine at $2 \mathrm{mg} / \mathrm{kg}$ (Fig. 1). The intra- and postoperative courses were uneventful. Due to premature rupture of membranes, the baby girl was born by cesarean section in week $33+3$ of gestation. The newborn presented with an Apgar of 8/8/9 and an initially sufficient spontaneous breathing. In the context of preterm birth, it developed an intermittent respiratory distress syndrome, as well as transient hyperbilirubinemia. In the further course, the baby developed a necrotizing enterocolitis, which was managed conservatively and resolved without sequelae. The further course was uncomplicated. Within the first day of live and again at the age of 2 and 4 weeks, the infant tested negative for HIV RNA (PCR) and was discharged home in good condition at the age of 33 days. Further HIV testing was performed at 3, 4, and 20 months post birth, and was always negative. Follow-up took place according to our standard protocol. At last check-up (corrected age of 20 months), the patient presented with a fully functional level sub L5 with partial innervation to $S 1$, allowing normal crawling and assisted walking (rollator). There was full resolution of hindbrain herniation, persistent macrocephaly, not requiring shunting, and a newly occurring cervical, nonsymptomatic, and hydromyelia. Voiding functions were normal.

\section{Discussion}

\section{Antenatal Management}

The most essential factor to reduce MTCT of HIV is a nondetectable maternal plasma viral load of HIV during pregnancy and at birth [8]. Therefore, undergoing HAART is absolutely necessary throughout pregnancy. This is also a sine qua non for any invasive fetal manipulation, e.g., in utero repair of spina bifida, amniocenteses, or chorion villous sampling. There is high evidence, that invasive prenatal testing does not increase the risk of vertical HIV transmission, in women under HAART when viral load is undetectable $[9,10]$. 


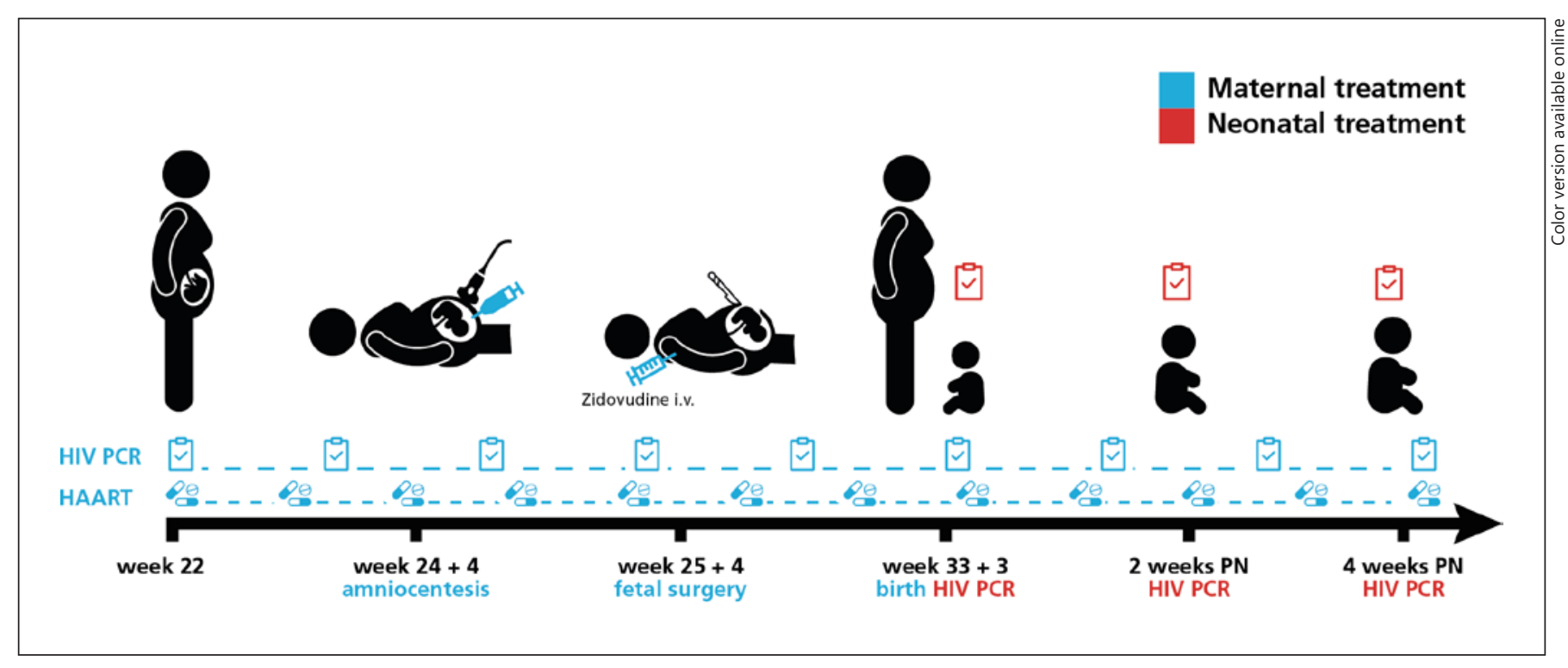

Fig. 1. Treatment concept: maternal viral load was closely monitored throughout gestation and was always below detection level, as was the viral load in the amniotic fluid shortly before the fetal procedure. Open fetal-maternal surgery was performed under perioperative intravenous therapy of the mother with zidovudine. Caesarian section took place in the $33+3$ weeks of gestation due to premature rupture of membranes. HIV PCR of the neonate was performed repeatedly postnatally and was always negative.

\section{Obstetric Management}

During fetal surgery, contact between maternal blood and the fetal wound cannot be avoided, entailing the risk of MTCT of HIV; however, a similar risk applies if fetal surgery is denied, and caesarian section is performed with an open back. In case of vaginal birth, the intrapartum administration of zidovudine is no longer indicated according to Swiss and British recommendations $[11,12]$, except in cases of unknown or high viral load. This is in accordance with French data, where treatment with zidovudine did not seem to reduce MTCT in cases of low maternal viral loads and absent obstetrical risk factors [13]. In light of the apparently very first prenatal intervention, we opted, nonetheless, for i.v. therapy with zidovudine at $2 \mathrm{mg} / \mathrm{kg}$ just prior to the procedure. The dose was chosen based on its conventionally used loading dose at delivery in HIV-infected pregnant women with a HIV$\mathrm{VL}>50$ copies/mL [14].

\section{Neonatal and Postnatal Management}

The Swiss guidelines [11] do not recommend neonatal antiretroviral HIV post-exposure prophylaxis (NEOPEP) for newborns of mothers with HIV infection that was completely suppressed during pregnancy. This is in contrast to some international recommendations [12, 15], which still recommend NEO-PEP in all cases of ma- ternal HIV. In our case, we did not prescribe NEO-PEP, in particular since the HIV RNA copy numbers were under the limit of detection. Infant HIV testing (PCR) was performed repeatedly after birth and was always negative.

\section{Risk-Benefit Evaluation}

Current ethical and regulatory requirements postulate that fetal interventions must be lifesaving or prevent devastating disabilities, and must involve low maternal and fetal mortality and manageable risk profiles [16]. Open fetal surgery poses a low risk of MTCT thanks to consistent HIV suppression. In the very unlikely event of an intraoperative fetal infection, HAART would need to be prescribed. Although this pharmacological treatment does not cure infection, it allows good quality of life.

As described above, the actual neurologic benefit from prenatal care of the HIV-negative infant is manifold. This is in line with the best-case scenario that we have elucidated in a recent analysis of 150 own cases [17], where $37 \%$ of patients required a shunt at 1 year, $12 \%$ exhibited normal bladder function at 4 years, and $84 \%$ were independent ambulators at 3 years. In sharp contrast, postnatal instead of prenatal care of the present case would result in a $>80 \%$ chance for a hydrocephalus shunt [2], a $>95 \%$ chance for incontinence [18], and a $>85 \%$ chance to become wheelchair dependent [17]. 


\section{Conclusion}

This is the first report on a successful open fetal spina bifida repair in a HIV-positive mother. Notably, MTCT of HIV was prevented and the infant has drawn a maximum benefit from prenatal surgery. This case is a surrogate for moving toward personalized medicine and away from applying rigorous, but outdated, eligibility criteria from former studies.

\section{Statement of Ethics}

The family has given written informed consent to publish their case. Neither of the subjects is identified by his or her real name.

\section{Conflict of Interest Statement}

The authors have no conflicts of interest to declare. However, Prof. M. Meuli and R. Zimmermann are Associate Editors of Fetal Diagnosis and Therapy.

\section{Funding Sources}

We thank the Uniscientia Foundation Zurich, the Zwillenberg Foundation Berne, and the Roesle and Meili Families for their support and interest in our clinical research work.

\section{Author Contributions}

J. Elrod: Investigation, writing of draft, reviewing, and editing. N. Ochsenbein-Kölble: Reviewing and editing. L. Mazzone: Reviewing and editing. R. Zimmermann: Reviewing and editing. C. Berger: Investigation, writing of original draft, reviewing, and editing. R.F. Speck: Investigation, reviewing, and editing. N. Strübing: Investigation, reviewing, and editing. C. Mohr: Art work, critical reading, and editing. U. Moehrlen: Supervision, reviewing, and editing. M. Meuli: Conceptualization, investigation, writing of original draft, reviewing and editing, and supervision.

\section{Data Availability Statement}

Data are generally not publicly available due to data confidentiality reasons. However, specific enquiries can be directed to the corresponding author.

\section{References}

1 Moehrlen U, Elrod J, Ochsenbein-Kölble N, Berger C, Speck RF, Mazzone L, et al. In utero hepatitis B immunization during fetal surgery for spina bifida. Fetal Diagn Ther. 2020;47(4): 328-32.

2 Adzick NS, Thom EA, Spong CY, Brock JW 3rd, Burrows PK, Johnson MP, et al. A randomized trial of prenatal versus postnatal repair of myelomeningocele. N Engl J Med. 2011;364:993-1004.

3 Selzman AA, Elder JS, Mapstone TB. Urologic consequences of myelodysplasia and other congenital abnormalities of the spinal cord. Urol Clin North Am. 1993;20(3):485504.

4 Möhrlen U, Ochsenbein-Kölble N, Mazzone L, Kraehenmann F, Hüsler M, Casanova B, et al. Benchmarking against the MOMS trial: Zurich results of open fetal surgery for spina bifida. Fetal Diagn Ther. 2020;47(2):91-7.

5 Mazzone L, Hölscher AC, Moehrlen U, Gobet R, Meuli M, Horst M. Urological outcome after fetal spina bifida repair: data from the $\mathrm{Zu}-$ rich cohort. Fetal Diagn Ther. 2020;47(12): 882-8.

6 Zash R, Makhema J, Shapiro RL. Neural-tube defects with dolutegravir treatment from the time of conception. N Engl J Med. 2018 Sep; 379(10):979-81.

7 Reefhuis J, FitzHarris LF, Gray KM, Nesheim S, Tinker SC, Isenburg J, et al. Neural tube de- fects in pregnancies among women with diagnosed HIV infection: 15 jurisdictions, 20132017. Morb Mortal Wkly Rep. 2020 Jan;69(1): 1.

8 Ellington SR, King CC, Kourtis AP. Host factors that influence mother-to-child transmission of HIV-1: genetics, coinfections, behavior and nutrition. Future Virol. 2011 Dec; 6(12):1451-69. NIH Public Access.

9 Wilson RD. Guideline no. 409: intrauterine fetal diagnostic testing in women with chronic viral infections. J Obstet Gynaecol Can. 2020 Dec;42(12):1555-62.e1.

10 Floridia M, Masuelli G, Meloni A, Cetin I, Tamburrini E, Cavaliere AF, et al. Amniocentesis and chorionic villus sampling in HIVinfected pregnant women: a multicentre case series. BJOG. 2017 Jul;124(8):1218-23.

11 Bundesamt für Gesundheit. Empfehlungen der eidgenössischen kommission für sexuelle gesundheit (EKSG) für die medizinische versorgung von HIV-infizierten frauen und ihren kindern. BAG Bulletin, Bern. 2018. Available from: https://www.bag.admin.ch/ $\mathrm{dam} / \mathrm{bag} / \mathrm{de} /$ dokumente/mt/p-und-p/richtlinien-empfehlungen/eksg-mtct-hiv.pdf. download.pdf/eksg-mtct-hiv.pdf.

12 BHIVA. British HIV Association guidelines for the management of HIV infection in pregnant women 2018. 2018. Available from: https:// www.bhiva.org/file/WrhwAPoKvRmeV/BHI-
VA-Pregnancy-guidelines-consultation-draftfinal.pdf.

13 Briand N, Warszawski J, Mandelbrot L, Dollfus C, Pannier E, Cravello L, et al. Is intrapartum intravenous zidovudine for prevention of mother-to-child hiv-1 transmission still useful in the combination antiretroviral therapy era? Clin Infect Dis. 2013;57(6):903-14.

14 European AIDS Clinical Society. EACS guidelines 2020. 2020. Available from: https: //www.eacsociety.org/media/guidelines-10.1_30032021_1.pdf9KN Accessed $2021 \mathrm{Jul} 18$

15 U.S. Department of Health and Human Services. Recommendations for the use of antiretroviral drugs in pregnant women with HIV infection and interventions to reduce perinatal HIV transmission in the United States. 2021. Available from: https://clinicalinfo.hiv. gov/en/guidelines/perinatal/whats-newguidelines.

16 Chervenak FA, McCullough LB. Ethics in perinatal medicine: a global perspective. Semin Fetal Neonatal Med. 2015;20(5):364-7.

17 Moehrlen U, Ochsenbein N, Vonzun L, Mazzone L, Horst M, Schauer S, et al. Fetal surgery for spina bifida in Zurich: results from 150 cases. Pediatr Surg Int. 2021;37(3):311-6.

18 Snodgrass WT, Adams R. Initial urologic management of myelomeningocele. Urol Clin North Am. 2004;31(3):427-34. 